\title{
Media Education in the ICT Era: Theoretical Structure for Innovative Teaching Styles
}

\author{
José Gómez-Galán 1,2 \\ 1 Department of Education, University of Extremadura, Avda. de Elvas, s/n, 06006 Badajoz, Spain; \\ jgomez@unex.es or jogomez@suagm.es \\ 2 College of Education, Ana G.Méndez University, Cupey Campus, San Juan, PR 00926, USA
}

Received: 17 April 2020; Accepted: 19 May 2020; Published: 20 May 2020

\begin{abstract}
The era of information and communication technologies (ICTs) in which we live has transformed the foundations of education. This article starts from the premise that there is a convergence between technologies and media that makes ICTs adopt strategies and forms similar to traditional media, especially in their quest to create influence on citizens. For this reason, curricular objectives should include a critical analysis of this new reality in order to train new generations. We propose, based on the traditional parameters of media education, a new theoretical framework for their development that includes innovative teaching styles to achieve these goals. We used a critical pedagogy methodology with a qualitative and descriptive approach through the analysis of the content of theoretical studies and field work through which to establish an innovative pedagogical structure. The main result is that the influence that ICTs have on children and young people today is as strong as, or stronger than, that traditionally received by the classical media, and that there is a lack of adequate framework to address the problem. In this sense, and as a conclusion, we consider that they must create critical attitudes before the power of influence that ICT has from very early ages, which generate problems like consumerism, addiction, cyber-bullying, and ignorance of the reality. This requires new teaching styles in line with the current social context.
\end{abstract}

Keywords: ICT; media education; critical education; teaching styles; digital literacy; holistic education

\section{Introduction}

We find ourselves in a new social reality in which all the parameters of our life are conditioned by information and communication technologies (ICT). This is by no means alien to education. It is not only that these new technologies and media can transform the teaching-learning processes since they are based on tools prepared for communication - which, naturally, is the basis of all formation-but they are completely modifying the habits and attitudes of the learners. From many perspectives, there is an urgent need for their proper integration into the world of education, at all levels [1-3].

So how can we educate in the era of ICT? How can we tackle this important issue? What changes are needed in current educational frameworks? We believe that there are two fundamental paths. On one hand, there is the methodological approach, in which ICTs are seen as educational tools that make it possible to improve educational processes thanks to their power. They can allow for the modification of teaching styles, making them more appropriate to the needs of the students. On the other hand, they are considered as an object of study. ICTs are not only instruments or tools, but powerful means of communication that generate a very important influence on children and young people, and even create dependence in their use and employment. For two decades, we have started from the premise, and we have ratified it with many works, both theoretical and in the field, showing a convergence between technologies and media that makes ICT adopt strategies and forms similar to 
traditional media, especially in their search to create influence on citizenship. For this reason, curricular objectives should include a critical analysis of this new reality in order to train new generations [4-6].

Although educational systems are sometimes hermetic and very faithful to tradition, they are also permeable enough to be modified to a greater or lesser extent by everything that transforms society. The digitization of information, which, due to its involvement in the economy, society, culture, politics, science, etc., is taking us into a new era in which the barriers of space and time are being broken down, also directly affects the teaching function [7]. It even transcends the barriers of the classroom itself to extend to the entire family environment [8].

In this sense, strategies and teaching styles are transformed by new possibilities that were completely unknown until a few decades ago. The current digital platforms and virtual learning environments (VLE) are implying new teaching models since they offer innovative teaching resources that did not exist before [9-11]. It could, of course, be extended to all the processes in which ICT plays a special role, especially in the field of e-learning, m-learning, u-learning, $p$-learning, all of which generate new training spaces (LMS environments, learning management system) in which teaching guidelines and models are adapted to a new way of teaching and learning that goes beyond a virtual representation of the traditional physical classroom [12-14].

In these contexts, classical learning styles can hardly be reproduced, although some characteristic elements of them (transmission of contents, communicative processes, motivation, interaction, formative assessment, etc.) are still present but take substantially different forms. Teachers must make an effort to adapt the characteristics of their traditional work to these new virtual environments, all of which generate great enthusiasm or, on the contrary, enormous frustration if the experience is not positive, creating the feeling of incapability in controlling the training process with the same efficiency as in the physical classroom. Training in the use of these new virtual spaces is fundamental, but it is not enough [15]. There are often other causes, which must be studied in order to find answers that favour the professional use of innovative environments generated by ICTs, in their multiple and complex possibilities [16,17].

We are of the opinion that teaching styles in e-learning processes (and its derivatives), always in distanced or semi-presential teaching processes, are very much conditioned by the very technological resources that support it. They certainly limit, in spite of their increasingly wide applications, the action of the teacher. It is possible, as we announced more than fifteen years ago, that virtual reality (VR) will establish teaching frameworks in the near future that are practically similar to traditional physical spaces, adding, in addition, new characteristics of an exceptional teaching power [18]. However, current VLE is still limited in its possibilities (as were the classic means of distance education), and although it tries to reproduce the quality of face-to-face teaching developed by a good teacher, achieving it is still not feasible.

It is true that excellent results can be achieved, hence the success of distance education for decades (and certainly the newest ICTs have updated and improved these processes). However, if we talk about teaching styles in a face-to-face context, in which the teacher carries out an adaptation to the needs of the student in multiple ways, along with the innate ability that the student may have to lead the teaching-learning process according to the needs that, by interaction, they establish, digital environments are still clearly behind. Moreover, on many occasions, they restrict and limit the action of teachers. Digitalization offers enormous possibilities, of course, but also serious limitations. In relation to teaching styles, we are faced with a paradigmatic example. This is another example of the fact that ICTs are not the panacea. It is essential to take this into account when analysing their characteristics and educational potential.. There are too many myths that remain in place $[19,20]$.

It is unquestionable, therefore, that the digital revolution has a direct impact on teaching action, as demonstrated in e-learning contexts. However, in this article, we want to go beyond this problem to focus on education in general, in all its dimensions, and above all, on face-to-face education, which practically covers all educational levels. We believe that the training that children and young people receive today is especially relevant, along with the influence that teachers have on it through 
their professional work. Thus, the question that really seems to be of the greatest importance to us is: is the digital revolution directly affecting face-to-face education? From this, a second question would arise, which is the object of our study: do teaching styles respond to this fact today?

If we start from the hypothesis of the great impact that ICTs have today on society as a whole, which is not unrelated to the world of education, it is essential to integrate them into teaching-learning processes [21]. This is not only for the training of students in the use of these important tools and means, but also for their analytical study as fundamental elements of our society. In this, of course, teaching styles are decisive. ICTs must be present in them, as a sign of their potential and, at the same time, to create critical attitudes in the students regarding their power of influence, which today leads to many important problems: addiction, alignment, cyber-bullying, etc. [22,23]

The strategies to carry out this objective are complex and of multiple possibilities. However, in this work, we defend that they would be carried out in a very adequate way based on the budgets obtained in the experiences that were carried out in the field of media education [24-28] fundamentally in the last few decades of the 20th century. The ICTs today, in a process of technological convergence, participate in all the characteristics of the classic mass media (at present we cannot distinguish between digital and traditional media, they are all subject to digitalization processes). Therefore, this basis would be fundamental. All this, in the context of what we could call holistic education [29-31], is a proposal of integral education centered on values whose principles and practices, at different educational levels, are suitable for this purpose.

\section{Materials and Methods}

The research was carried out under a qualitative and descriptive approach through the analysis of the content of theoretical works and field research in order to establish the framework for the structuring of a new pedagogical proposal. Essentially, it seeks to use the classic frameworks of media education applied to the current context, starting from the fact that ICTs are powerful communication media that have merged-in a process of techno-media convergence-all the instruments, media, channels and languages of communication. Media that were independent decades ago, such as the cinema, radio, television or the press, are today integrated into the digital medium and have been transformed by it, homogenizing many of their previously distinct characteristics.

This methodological approach encompasses all stages of education, from primary school to university. Although from a theoretical perspective the fundamental bases are common, in practice they must be adapted in an adequate manner to the objectives and needs present in each of them. The current impact of ICT on children and young people is so evident that we are talking about a global problem that is tangential to what we understand today as education and training. Of course, teaching styles must be in line, at all educational levels, with this new reality in which we live and in which the digital paradigm dominates everything.

From a methodological perspective, and in general, we use the main methods of so-called critical pedagogy, which has been applied in recent years mainly in the Latin American context and whose antecedents we can place, among other authors, McLaren [32] and Giroux [33], analyzed extensively in recent years [34,35]. Naturally, in this work, all kinds of political or social considerations have been left out, sometimes integrated into these methodological processes. In our case, we establish as a basis some of the objectives of this methodological approach, such as the analysis of how students read and understand the different languages present in the cultural codes existing today [36]. We are talking about a perspective related to praxis, that is, educational practice, since teaching styles must be adapted to a new reality in which the digital world is so present in all areas.

The aim would be to train students to be critical of the power of influence of the powerful media that ICTs represent today, and the influence that they exert on them, in order to create more critical, fair and supportive societies. This is also why it is very much connected to Freire's educational postulates $[37,38]$ although, as we have said, without the political connotations with which they have sometimes been viewed. The methodological structure to which we adhere is in the sense of its capacity 
for change or transformation, starting from a concrete practice. That is, the modification of current teaching styles into more practical and effective ones in the current digital context. In all that this implies of autonomy, dialogue and research of the teaching staff in their search to form people who are more critical and reflective of reality.

We must insist, therefore, that within this methodological framework, all the postulates of critical pedagogy are in no way assumed. As in all methodological currents, there are many lines and derivations, developed according to each author. In our case, we consider that there are elements, very present in researchers who have followed it, that could however be very questionable in the context of media education and, in general, in any educational process. For example, and we agree with Buckingham [26]: its synthesizing political and theoretical ambitions; its neglect of educational practice; and its evasion of questions of power and authority. Far from employing this methodology in the setting of a political context, which never seems appropriate to us, we argue that it should be articulated to establish a basis of educational practice appropriate to school needs. In this area, it has elements of great utility for the creation of new teaching styles according to a new reality in which informative and communicative processes have so much relevance and influence.

On the other hand, like any descriptive methodology, and in this case based on the analysis of documentary sources and field work from a theoretical and philosophical approach, it of course has limitations. One of the most important ones, when applied to a complex body of knowledge such as media education - and with so many conditioning factors, as we have pointed out-is that there may be contradictions in existing approaches. In this way, the search for objective results will be distorted. In this sense, it should be noted that media education has never been homogeneous. It is precisely its tangentiality that has been used in many ways and for many different purposes. However, in this paper, we focus on a minimum of common characteristics. Among them is the need for the media to be seen as an object of study and not just as a teaching tool [4]. It is necessary to integrate it into the curriculum, since it constitutes part of the integral formation of a person [6]. Most of the contradictions that exist in media education schools are related to elements of a political, ideological, etc., nature, which, as we have pointed out, we try to dispense with. It is precisely these determining factors that have often limited its application in practice and, in particular, that its links with the current digital paradigm and, above all, teaching styles have not been adequately explored.

In general, this whole framework in the search for a construct also fits within the methodological parameters of discursive theory. In it, teaching styles seek to learn by communicating, relating, recognizing each other, etc., for the formation of moral subjects that involve all members of the educational community [39]. We are talking, therefore, about frameworks of holistic education that face current problems in a global manner, based on the fact that all of them are intercommunicated and interdependent.

\section{Results}

\subsection{Learning Styles in the Classroom: The Media Education Model}

Throughout history, fundamental moments in the development of human media have occurred, such as the birth of writing - as the apex of the Neolithic Revolution, which in its origins naturally meant a radical transformation of the means of production-or the printing press, in the antechamber of the Industrial Revolution. Of course, these facts had a decisive impact on education, and especially on teaching function. There is no doubt that the same thing will happen due to digitalization (which could lead us to speak of a Digital Revolution) that is taking place in our world. In all cases, and independently of profound changes in other dimensions (modes of production, economy, social and political movements, culture and religion, etc., all of them intercommunicated and interdependent), the communicative processes played a leading role in these milestones in the history of humanity. Certainly, over hundreds of years there was a gradual growth in the possibilities of communication, and the characteristics and means that constituted it were diversified. 
In the 20th century, accompanied by the technological development that made this process possible, we find the existence of multiple communication media that use the most diverse systems and languages: writing, sound, image, multimedia techniques, etc. Precisely at the end of the last century, however, thanks to the development of computer science and telematics, technologies focused on the automatic processing of information and its transmission through networks-whose initial objective was, and we insist on it, the optimization of management-another decisive moment in the transformation of the media was being forged: the digitalization of information, which leads to the convergence of the media.

Today, in this first half of the 21st century, we are witnessing, as astonished spectators, a new revolution in human communication processes. We read the press at the beginning of the morning; watch the episode of our favorite TV series on the metro on the way to work; listen to the listeners and participate in the radio programme of the local station; buy a ticket to Steven Spielberg's latest film production and watch it, with the addition of stereoscopic glasses, while having a drink on a terrace; or write-perhaps with an effective speech recognition system-a new entry on our favorite blog or social network while we go home. Most of these possibilities are already technologically feasible, which clearly places us in the inertia of the above-mentioned convergence. They open us up to a clearly different communicative world, very complex compared to its apparent simplicity, unknown in its forms, strategies and means of production and technological development for most of the population, a world in the hands of very powerful media lobbies aware of the power not only of information, naturally, but of its transmission.

For today, there is no more obvious proof than the example we have given that ICTs constitute the whole of the human communication media or, if we express it more precisely in the established theoretical framework, the support of the only existing medium (the digital medium). Inside it, the traditional owners of communication, with identical objectives and interests to those they have always aspired to, exercise their longed-for monopoly. Given this panorama, which is characteristic of our society, the digital society, the technological society, the communication society, the educational repercussions of all of this are undeniable [40-43]. They must be contemplated entirely in the processes of educational research, because ICTs are not only tools with possible and theoretical attraction for their use in teaching-learning processes.

They are, no more and no less, the essence of our society, the essence of the world of the 21st century. It is necessary to know them in depth if we really want to know our world. This can only be achieved in educational contexts. Let us not forget, moreover, that education is, above all, a process of communication. Regardless of the above, in the digital paradigm that leads to techno-media convergence [44], what is important in itself is not the medium (which today is a single medium, the dream always pursued by power and today made reality) but the message. This keeps McLuhan's classic maxim more alive than ever [45].

There is no doubt, of course, that a revolution has taken place in our lives. Just by looking at a street, or travelling on the underground, or at our work table, or at the customs and games of children today, we will realize that, gradually, almost without appreciating it, subtly, this unique digital medium has infiltrated our existence. It has gone much further than the solid theoretical frameworks presented at the time by authors such as Mattelart and Mattelart [46], Negroponte [47], Castells [48], Echeverría [49] or Bauman [50] when they described the communications revolution we are witnessing and its influence on all dimensions of human activity. Observing the reality that surrounds us, it would seem that rather than it being a medium at our service, we are the ones who are at the service of that medium.

All this, of course, has consequences of unusual transcendence in the field of education and, in particular, in educational research. First of all, we are convinced that, today, all study with ICT must be considered within the parameters of media education, in the classic sense of the term. This is because it is undoubtedly the best (and perhaps only) way to fully understand the role and importance of ICT in our society, and the influence they exert through their sophisticated messages. They are 
very powerful means of communication. On the other hand, the theoretical postulates and practical experiences carried out in the context of media education must be adapted to the new reality and have a decisive influence on teachers' teaching styles, making them experts not only in their knowledge and didactic use but, above all, in creating critical and constructive attitudes among students in the face of the power of influence that ICTs have today. This is because, certainly, and we are convinced of this, if there is no education in this respect, it will condition the freedom of the individual.

This is the key: it is not a didactic problem; it is an educational problem. Parallel to this main objective, the individual must be trained in the useful and productive use of the media, from their use in a professional environment to simply as a consumer in a leisure context. We insist: today ICTs are not management tools, as they might have been in their origins, but effective means of communication at the service of certain interests (for their owners we are first and foremost clients, consumers, voters). Media education is therefore more necessary than ever-it must be the basis for any scientific study of this problem.

Fortunately, in recent years, trends in media education have strengthened its practical vision. Apart from controversies or constraints, which were very much present in previous decades, it is necessary to establish a basis for its use and development. As Salomaa and Palsa [27] defend, the versatility of media education can be an advantage. To a certain extent, it allows for its adaptation to the needs and objectives of each educational system, educational stage or centre. Certainly, it is related to cultural and social trends that must be taken into account, but this does not prevent it from being necessary to re-evaluate the activities, objectives and operational methods for its application. Following the study of these same authors [27], who synthesize several of the trends that we also present, these would be the questions that should mark the evolution of media education today:

- Technological advances. The spread of digitization in all areas of society highlights the importance of assessing the reliability of information. Advances in artificial intelligence, the Internet of Things, datafication, algorithms, augmented, extended and virtual reality, robotization, etc., among many others, present new questions for media education.

- Media use habits are changing. The media is used very differently today than in the past. The changes are related to social media, gaming, gamification and e-sports, to mention a few. It is also important to be aware of the changes in media markets, such as the concentration and international character of operators.

- Media literacy requirements are changing. In addition to different kinds of media literacy, other types of literacy should also be taken into account in media education: the traditional ability to read and write text, critical literacy, digital literacy, data literacy, visual literacy and multiliteracy.

- Competence requirements for media educators will change. Trends in media education concern digital and lifelong learning, peer learning, the broadening of the target groups of media education to cover all age groups, and the diversification of terminology

- Changes in society and culture affect media education. Media culture is internationalizing, which means that it is increasingly important to consider globalization in media education. The ageing of the population and multiculturality affect the target groups and topics of media culture.

Alongside these trends are a number of important challenges for media education today [27]:

- Media education lacks resources. Lack of resources is frequent, which conditions its application (organization of activities, hiring personnel, allocating working hours, purchasing of equipment and materials, competence development, etc.). This, in turn, contributes to the fragmentation of the field.

- Collaboration, coordination and networks in media education are insufficient. Better collaboration, coordination and networking would improve the efficiency of the work, develop the activity, help take into account the different perspectives of media education.

- There are shortcomings in competences related to media education. The field of media education is broad in terms of topics and perspectives. Shortcomings in competences may impact certain themes, 
topics or perspectives of media education and limit its coverage even from the perspective of target groups.

- Media education is fragmented. Media education cannot be limited to apply to specified target groups only.

- Media education is not systematic enough. In order to be pervasive and consistently developing, media education must be systematic.

- Changes in society and media culture challenge media education. Inequality between people, social exclusion, climate change, polarization, racism and discrimination are social problems that require awareness in media education.

- Media education is not known or valued enough. Awareness of media education still needs to be improved. Media education as a term may not be familiar or it may be understood too narrowly.

These trends and challenges in media education can be accepted by virtually any specialist today. They are evident beyond the various approaches that may be established. We are faced with a problem that is of enormous importance in today's society and in the face of which education systems cannot remain on the sidelines.

\subsection{Critical Analysis of (and with) the Media in Education}

It is therefore necessary to start from this premise: media education is more necessary than ever. Although we will go deeper into this perspective that we propose below, we can now anticipate that the classic contributions of authors such as Masterman [24] or Buckingham [25] can serve as a methodological and structural reference for the current study of ICT, in relation, of course, to their presence in the field of education.

Although we agree that an updating of traditional designs is necessary, as advocated by Burnett and Merchant [51] or Greenhow, Sonnevend and Agur [52], it is no less true that the essential bases must be the classical ones. Today the digital medium (let us take the Internet as a reference) not only has all the impact characteristics of the classic media, but the digital multimedia revolution has allowed it to offer new and complex forms of expression (in which audiences, moreover, become active agents) that must be urgently analyzed in order to understand, in all its dimensions, the importance of its authentic presence in society and the educational needs that all of this implies. This is without forgetting that we are dealing, of course, with a medium of media (hypermedia), or perhaps it would be better to indicate, as we have pointed out, that we are simply referring to a single medium (digital) with different channels of communication.

Media education, therefore, because of its experience and results, should guide all studies that focus on didactic and educational actions. It is clearly focused on a pedagogy of the media oriented to the educational practice, and not reduced to an exclusively theoretical construction, as Buckingham himself [25] already made clear in his time. Practical experiences of its application in the current media reality are urgently needed.

On the other hand, and in parallel to what has been said, we should be aware that the relative novelty of digitalization and the multimedia revolution means that different groups of media are apparently presented, but that (as we are saying) this is not essentially real, with the classic media, on one hand (which would be considered to belong to the field of media education), and those developed from the emergence of computer science and telematics, without having any significant analogical background, on the other (and which would open up different lines of research in the field of educational technology).

It is for this reason that there is an abundance of scientific literature that treats the latter as independent elements, since they are considered with very different objectives and methodologies, as if we were speaking of means and resources that-only because of their contemporaneity (and not for other reasons of greater relevance)—imply a radically different treatment from the previous ones [6]. Thus, there are many studies that develop experiences with computer programs, the Internet, virtual 
communities, $e$-learning, $b$-learning, $m$-learning, $p$-learning, $u$-learning, social networks, MOOC, etc., that are detached from their true significance in our society, becoming only didactic support tools (didactic resources) or instructional systems without taking into account what their main purpose is in today's world, the interests they serve, their influence on the population or the possibilities of analysis, understanding and, in short, critical use of them [53].

The result of all this is that, paradoxically, the same mistakes are being made that happened when the first steps were taken in the study of the media in education, and which were overcome throughout the 20th century. For lack of space, I will focus on just one of them, which we believe is sufficiently illustrative, and that is to consider that these media and tools, precisely because of their novelty, will address a very important part of the ills of education, or will accelerate their improvement. Even in people of an optimistic nature, they would be presented as the definitive solution. The example must be set at the beginning of the last century, specifically in the 1920s, which were indeed a time of unbridled optimism. The most terrible disaster in the history of humanity, the First World War, had just ended, and all nations were embarking on exorbitant construction and growth projects, in an era of peace and hope. Even if it was precisely this excess of confidence that led to the creation of giants with feet of clay (which could have been contemplated by all in the crash of 1929, one of the main causes of an even greater catastrophe such as the Second World War), the truth is that certainly new initiatives were taken in all areas of life, including, of course, education.

It was a time of continuous technical and scientific progress, as it was with the media. There was a real expansion of the same, to the new needs of a society in which leisure was increasingly important. The press, the radio, the cinema, etc., began to form an indissoluble part of daily life. Education, which in spite of being permeable to other social systems, finds it difficult to integrate authentic innovations, seen in these media, of a structure similar to didactic processes (they develop, in the same way, communicative processes) extraordinary and hitherto unknown possibilities. One area of the media that was experiencing a major boom was the cinema. Relatively recent, although two decades old (similar to what happens today with personal computing, for example), it was shown to be an ideal tool for teaching.

It would make it possible to achieve educational objectives that were difficult or impossible for teachers to achieve, the possibility of filming classes that could be shown in any context and at any time, the continuous exchange of teaching experiences, the creation of film libraries with masterclasses by numerous renowned specialists, etc. There was even a sense of a before and after in the world of education, the birth of an audiovisual revolution that would completely remove the foundations of teaching, and that could perhaps be the definitive solution to many of the problems, such as the shortage of teachers in the face of the growing massification of education systems.

It was necessary, however, to check these possibilities from a scientific perspective. Freeman [54], a professor at the University of Chicago, rigorously undertook this task. After carrying out a three-year experiment, consisting of a comparative study in which, on one hand, the use of films in American public schools was analyzed together with the didactic results obtained, and which were compared, on the other hand, with those thrown by other traditional means in which this technology was dispensed with or, at most, very simple iconic means were used (graphics, photographs, etc.), reached a conclusion that, offered in the now classic work Visual Education, a Comparative Study of Motion Pictures and other Methods of Instruction, and published almost a hundred years ago — at the beginning of the 1920s-we consider absolutely valid today: there was an undeniable educational value in that medium (in this case, the cinema, but today we can apply it to the digital medium) but only if certain conditions were present for its correct use [44].

All the initiatives carried out at that time were decisive: what is important is not the medium itself, but the use made of it, the characteristics of the students, and other related variables. The long history of media education, from that time until today, has only corroborated these initial results. It is clear, therefore, that what is truly fundamental to education is the teaching style of the teacher, his or 
her creativity, initiatives and innovative processes, the clarity of the objectives that education should really be. However, this is not being strengthened, quite the contrary.

\subsection{Integrating ICT into Education through New Teaching Styles}

The situation today is undoubtedly very similar to that of the time when Freeman developed his studies. Digitization has meant a new explosion of media (in this case, which is more shocking, of a single medium), and from multiple spheres (social, economic, political, etc.) there is a wide range of alternatives and possibilities. Once again, education is receptive to all this. The problem, which arises again, is to consider intrinsic properties that are completely detached from the educational context of application, and from the general lack of knowledge of their functions, objectives, interests and processes.

Just as the cinema was not created in its origins for education, and that already in the twenties of the last century, in Freeman's time, it ended up becoming a mass spectacle essentially oriented towards entertainment, and the current digital medium was not originally conceived for use in educational contexts either. However, like the cinema, it can be used under certain conditions. Therefore, the important thing, again, would not be the medium itself, but the use made of it. Unfortunately, the euphoria of technological development presents multiple proposals that are completely out of context with the slightest pedagogical logic.

It is frequent that we find, accompanied by all kinds of paraphernalia and fireworks, initiatives and projects that, theoretically, are said to change educational processes as we know them. we frequently find initiatives and projects that, theoretically, are said to change the educational processes as we know them. They can be of all kinds: institutional programs for the integration of new technologies (in which a very broad group of professionals and technologists participate, but in which educators are not infrequently a minority, if they are present at all); international macro-projects in which the use of the new technologies is prioritized (the term is still used because of its prodigious evocations) as opposed to traditional methodologies (as if, in short, they were different dimensions); molecular experiences, offered as a revolution, and in which their adoption is called for in all kinds of educational contexts, regardless of level, initial training or social characteristics, etc. A lot of money is invested in proposals that are considered definitive, wrapped in magic words (e-learning, m-learning, b-learning, digital whiteboards, e-books, online campus, VLE, digital platforms, virtual and augmented reality, ECTS credits, etc.) and that in many cases do not improve traditional educational processes.

All these proposals require methodologies that, as it is underlined, need these innovative tools in an essential way, which announce, in general, a new education, a new way of teaching, invalidating what until now has been this noble art and honest science as obsolete and outdated. It is imprudent to embrace extremes; virtue is always at the point of equilibrium. It is true that the use of digital instruments, the support of the only current medium, can allow us to improve the quality of teaching, that is undoubtedly true, but only if it is carried out in the right pedagogical conditions. This requires that the experiences and research developed for this purpose do so within the parameters of rigorous and contrasted scientific analysis, starting from all the knowledge that has been accumulated over decades, but always from the perspective (here is the key) that education is not about informing or even training. Above all, always bearing in mind what is, in essence, the function that this extremely powerful medium has in our society, what its objectives are, how it influences it, etc., in short, a critical reflection in which the teaching professional is above all a thinker, a trainer, an innovator, an intellectual, and not exclusively, an ICT technician.

Media education, a media pedagogy, must be the guiding light, in the context of a holistic and integrated education. From the perspective of a critical pedagogy, it can be shown that there are no miracle recipes, and that we must move forward little by little. In this vertiginous society in which we live, everything must be immediate, fleeting, instantaneous, and it seems that this must also be the case in education. 
Thus, it is sold as real that a person can learn a language in six months, complete his doctorate in a little more, or learn the handling of a sloop properly, thanks to e-learning, online tutoring, tablet or reading the main blogs that appear if you do your search properly on Google. There will always be some magic recipe supported by ICT. Of course, behind all this we will find huge economic interests supported by pillars much closer to marketing and consumer strategies than to the slightest educational quality.

However, the basis of any educational process, of Education (and here we must use capital letters) must be the teacher, the real reference framework of the student. Teachers should have the greatest possible freedom in the exercise of their professional duties, without being subject to limitations and corsets that are often imposed by ICTs themselves.

It must make use of them whenever necessary for the suitability of the teaching-learning process and, above all, for integrating some fundamental elements into our world, which must be analyzed and studied in as much depth as possible. In a holistic, integral and integrating context, seeking the development of values in our society, of which the teacher must be, as a model, their main reference.

What, therefore, can we learn from the way in which ICTs are currently being integrated? First of all, they go completely beyond the traditional role of teachers, who are disoriented, often lost and frustrated, as shown by so many studies [55-59]. The problem is that attempts are being made to integrate by training teachers in tools that are sometimes not necessary. Students often have a much higher technical mastery of them than their own teachers [60].

Above all, the way is to understand them as an object of study. Not because of their possibilities as educational tools, but because of their decisive presence in society. What was done in media education with the cinema or radio can be done with all ICTs. For example, in primary education it can be shown that many of the technological products are simply that, products. A film full of special effects is not reality, but recreates reality. Social networks are not reality, but recreate reality [61].

In this context, the teacher should have, above all, full freedom to make a critical analysis of these tools, modifying their teaching style, which should not be conditioned in any way by objectives of instrumental use, as is happening in many cases in the curriculum. The use of ICTs should only take place when it is required, necessary, or contributes to achieving higher quality educational objectives. In all cases, this means ICTs should be analyzed with all that they imply in the social context. We would find, in this case, an authentic education for the media that follows the classic postulates of their theories applied to the world today, in the context of critical pedagogy and holistic education that we have previously written. Paradoxically, we are talking about new teaching styles based on the most classic and effective ones.

\section{Discussion}

In short, ICT can be appropriate in certain teaching-learning processes, but it is necessary to establish the most appropriate teaching strategies not only for their effective integration into educational settings, but always bearing in mind the context of adequate training for the society of the 21st century $[44,61]$, and to define, as Balazak [62] defends, what the competencies and scope of the professional work of teachers are in the face of this problem. The need to have pedagogical skills in media education today, as developed in studies by Fedorov, Levitskaya and Camarero [63], Grandío-Pérez [64] or Antonelli, Di Risio and Di Felice [65], are important for the adequate training of students at different educational levels. Let us not forget that this is essentially a task of the teacher (in the academic field) as well as of the families (for the initial stages of education), in line with what is defended by García-Ruiz, Matos and Borges [66] and ourselves [44].

In this context, therefore, an interdisciplinary approach is essential, with new perspectives in the field of research within an intra- or supra-educational dimension adapted to the current situation $[53,67,68]$. We must take into account, and this is one of the conclusions we wish to reach, that teaching styles (in our case, as we have developed, we defend the characteristics of holistic education 
and use in it the experiences produced in the field of media education) depend on both experience and previous training. Educational research can therefore make a great deal of difference.

As Simsek [69] showed, educational technologists focus on considering ICT as a learning resource. We can add that on many occasions they also appear as prodigious recipes that would be the antidote to many problems or educational difficulties. This cannot be the way. Not only because the presence of the digital medium in education must go far beyond instrumental use, to enter the sphere of the analytical, critical and intellectual, as a means of knowing the world and reality, but also because on many occasions the demand for the use of them (in a misunderstood quality of teaching) conditions the teacher enormously and, paradoxically, his or her didactic freedom and creativity [44]. For any imposition that conditions the teaching environment with which the teacher is most comfortable cannot yield positive results - even more so if there is no previous solid training that has led him/her to discover an adequate teaching style in accordance with the characteristics of current educational processes.

Of course, we are not saying that the work of teachers cannot be effective with the digital medium, quite the contrary. What is needed is for it to be employed from an entirely pedagogical and correct perspective. Let us think, for example, of the possibilities of the press. It would not be the same to have a newspaper in the classroom with which to develop a specific educational activity, as it would be to have access on the Internet to the editions, permanently updated, of four or five newspapers with which to take advantage of all the possibilities offered to us for, say, the critical analysis of the news (reading the same news in the different newspapers, measuring the space dedicated by each one of them, treatment, sources used and contrast between them, etc.). The Internet, of course, will have made this task easier for us (otherwise we would have had to acquire various copies, highlight and cut out the content, etc.) but, in essence, the process of study and pedagogical use of ICT could be based on the classic structures of a media pedagogy, and lead to a greater and better knowledge of the social reality in which the student's life unfolds.

We can extend all this to any other recent computer or telematic tool. Let's just think about social networks. We could use any of them for any educational development in order to enhance interactivity, group work, creativity, motivation, etc., and it is certain that the results-if everything has been properly designed from a pedagogical point of view-will be positive, but we cannot leave out the impact that they have on society, and especially on their influence on children and young people. We must take advantage of their use as teaching resources to make them, in parallel, the object of study, of the analysis of their characteristics, of the use that the student makes of them in his life, of the advantages but also of the possible dangers that they contain. It would even be appropriate to first use social networks under educational control (such as Edmodo) as a preparation for the knowledge and handling of the most widespread social networks, of which there is no doubt that children and young people will become consumers sooner or later (such as Facebook, Twitter, Instagram or any other that is successful in the future). We would therefore speak of a comprehensive education in which ICTs are considered in their true social and educational dimension, in the sphere of techno-media convergence [61]. In short, a correct work with the digital environment from a holistic and integral perspective.

Today, studies continue to be carried out in the field of media education [70-74], and these lines of research should be strengthened. The training of future teaching professionals should be framed in this context. Uniting ourselves, for example, in the Internet as a whole, would not be the same as a professional qualification process that focuses our attention on what the network of networks can offer us for the development of teaching-learning processes, as well as showing what the Internet is and knowing what it means for our world today (what is really behind it). It is extremely serious that there are processes of initial and continuous training of teachers in ICT based only on the technical handling of a series of instruments and tools. Many educational policies do not consider them to be anything more than teaching aids, certainly (in line with so many similar lines of research), but even in these cases there is a complete mismatch between teaching needs and the use made of these media.

Thus, and instead of training as critical agents, in interpreters of our society that allow for a true integral education of the person, of the knowledge of today's world and of the consequences of 
the revolution that the techno-media convergence implies (that is, of teachers and students perfectly qualified for the educational challenges of our society), there is a tendency to create users of office programs, social networks and amateur designers of graphic presentations and web pages (Gómez Galán, 2011). A complete review of teacher training policies is needed, as well as an understanding of what it really means to integrate the digital environment into education.

The teaching styles of teachers cannot be forced to introduce instruments whose use and possibilities the teacher has doubts about, much less limit their true potential, especially when it has been shown that teaching styles condition learning styles [75-77]. The teacher must, above all, know the ways to approach student learning, their attitudes, values, cultural differences, skills and study habits [78]. From this, we can build teaching styles adapted to the new reality. The first thing is to recognize the power of ICTs in our society, and to create critical attitudes in students towards them. On the one hand, to know their influence strategies, which generate problems of great relevance and complex solution (addictions, alignment, promotion of school bullying, etc.), which are turning out to be very serious. And on the other hand, to know that they undoubtedly condition the very processes of teaching and learning, since students see the classroom as a world apart from the reality in which they live, dominated by ICTs.

\section{Conclusions}

We need a critical and reflective teaching staff, which leads us to think, to analyze, to reason, to infer, to students who are used to 140-character messages, with creative freedom, motivation, passion for teaching, recovering the leading role that the teacher always had as an organizer of knowledge, counselor, helper, model and example.

Unfortunately, nowadays, wrapped up in the artificial euphoria caused by the emergence of the digital paradigm, all these elements become secondary, and the teaching professional is seen as one more instrument that should be at the service of that one medium, the digital medium that surrounds and conditions everything. Today, many currents and studies only focus on the benefits of digitization, in which the teacher is only a tool, a mere extension of the process. They argue that this is where the real quality of teaching lies, regardless of the drawbacks that may exist. When the ideal, of course, should be to analyze the problem in its entirety. There is an urgent need for new research approaches that address the problem from a holistic perspective, in all its complexity and extension.

On the basis of a meta-analysis, supported by the principal studies and research in education for the media analyzed in this work, it is possible to defend a necessary reorientation of curricular policies and the integration of new teaching styles in instruction processes. Of course, from the approach we offer, in which we understand ICTs first and foremost as powerful media with an unquestionable protagonism in the current digital paradigm. The main elements that we have been able to identify (need for an analytical approach to the media; training to distinguish between reality and fiction; creation of critical attitudes towards media messages; education against the direct influence of ICT to prevent addictions; knowledge of the interest of the media to change consumption habits, attitudes and/or thinking; relationship between values and media culture; etc.) are common to all media education processes, and today they are more necessary than ever.

In short, we are faced with a problem that should play a greater role in educational research, both in its theoretical and practical aspects. There is a series of conclusions that we can synthesize in relation to the objectives and goals undertaken in this work:

1. Today the digital paradigm, of hands on ICTs, has transformed the foundations of society and, consequently, of education.

2. The convergence between technologies and the media has led to the adoption of strategies and forms of ICT similar to traditional media, coinciding in their objectives of social, cultural, economic, political influence, etc. 
3. An analysis of this reality, which has such an impact on the lives of citizens, needs to be carried out in schools. ICT cannot be considered exclusively as a didactic resource. They must be, above all, an object of study.

4. Today, any study with ICT must be considered within the parameters of media education, in the classic sense of the term.

5. Media education encompassing all ICTs must be offered at all educational levels, naturally adapted to the characteristics and objectives of each stage. Its development would help to tackle problems such as excessive consumerism, addictions, cyber-bullying, processes of disinformation and fake news, etc.

6. In the context of a media education of a holistic nature-through an approach that considers all problems as interdependent-students will be able to understand the role and importance of ICT in our society but also to know the influence of its sophisticated messages.

7. One of the most effective means of integrating ICT into the curriculum, in addition to specific educational policies, would be teacher training and, in general, the transformation of teaching styles, which should be adapted to the new social reality in which we live.

8. Teaching styles must be based on the autonomy of teachers to carry out their professional work through dialogue, knowledge of the classroom and its students, innovative methodologies, etc., seeking to create people who are more reflective of the world around them and the information they receive.

9. The problem, in essence, is not didactic, but educational. Today, ICTs are not management tools as they were in their origins but effective means of communication at the service of multiple interests (and in which citizens are, above all, clients, consumers, voters).

10. In classroom work, ICT cannot be integrated solely as a teaching medium. Teachers must be trained not only to use them instrumentally, but to analyze them like any other element of our world that must be known in order to be taught. This is how they would really be integrated into the teaching styles that are required today and with the guarantee that they will serve both training and education.

Without a doubt, the future of education lies in the development of a holistic model that also takes into account all that media education has to offer, since our society today is essentially a media society. The teaching styles of teachers, based on knowledge of our world, are above all based on freedom, motivation and creativity. To use all the beauty and wonder that this profession has always had, adapted to new times and recent needs. However, to do this we would have to answer the most important question, and that is to be sure that this is really of interest to the system.

Finally, and with regard to the limitations of the present study, it should be noted that a more in-depth meta-analysis is desirable and could occupy future work. It is also possible to carry out this meta-analysis using quantitative parameters and statistical analysis of the summarised results of a larger sample of research studies, in line with Glass' postulates [79] regarding this methodology. This work could be supported by the results and conclusions obtained in this study. Based on the broad and rich theoretical conceptualization of the use of meta-analysis in the field of educational sciences [80-83], we will be able to continue studying in depth a problem that is not only of great interest for the present, but will also become increasingly relevant over the years. We are undoubtedly at the dawn of an ICT era that will transform social and, naturally, educational standards.

Funding: This research received no external funding.

Conflicts of Interest: The author declares no conflict of interest. 


\section{References}

1. De Brock, E.O. Integrating Real Practical Experience in ICT Education. J. Inf. Syst. Educ. 2020, 12, 2.

2. Pisoni, G. Strategies for Pan-European Implementation of Blended Learning for Innovation and Entrepreneurship (I\&E) Education. Educ. Sci. 2019, 9, 124. [CrossRef]

3. Cha, H.; Park, T.; Seo, J. What Should Be Considered when Developing ICT-Integrated Classroom Models for a Developing Country? Sustainability 2020, 12, 2967. [CrossRef]

4. Gómez-Galán, J. Tecnologías de la Información y la Comunicación en el Aula; Seamer: Madrid, Spain, 1999.

5. Blanco, S.M. Design of educational web pages. Eur. J. Teach. Educ. 2004, 27, 99-104. [CrossRef]

6. Gómez-Galán, J. Media Education as Theoretical and Practical Paradigm for Digital Literacy: An Interdisciplinary Analysis. Eur. J. Sci. Theol. 2015, 11, 31-44.

7. Spiteri, M.; Rundgren, S.-N.C. Literature Review on the Factors Affecting Primary Teachers' Use of Digital Technology. Technol. Knowl. Learn. 2018, 25, 115-128. [CrossRef]

8. Macia-Bordalba, M.; Bochaca, J.G. Digital media for family-school communication? Parents' and teachers' beliefs. Comput. Educ. 2019, 132, 44-62. [CrossRef]

9. Galán, J.G. El Fenómeno MOOC y la Universalidad de la Cultura: Las Nuevas Fronteras de la Educación Superior. Revista de Curriculum y Formación del Profesorado 2014, 18, 73-91.

10. Rienties, B.; Giesbers, B.; Lygo-Baker, S.; Ma, H.W.S.; Rees, R. Why some teachers easily learn to use a new virtual learning environment: A technology acceptance perspective. Interact. Learn. Environ. 2014, 24, 539-552. [CrossRef]

11. Matosas-López, L.; Franco, J.C.A.; Gomez-Galan, J. Constructing an Instrument with Behavioral Scales to Assess Teaching Quality in Blended Learning Modalities. J. New Approaches Educ. Res. 2019, 8, 142. [CrossRef]

12. Galán, J.G.; Parras, J.P. Luces y Sombras del Fenómeno MOOC: ¿Representan una Auténtica Innovación Educativa? Revista de Pedagogia 2017, 38, 35-51.

13. Parras, J.P. Nuevas Tecnologías e Influencia del Ambiente dentro del Proceso Enseñanza-Aprendizaje: Impacto de los Cursos MOOC en Educación. Int. J. Educ. Res. Innov. 2016, 6, 176-186.

14. Waheed, H.; Hassan, S.-U.; Aljohani, N.R.; Hardman, J.; Alelyani, S.; Nawaz, R. Predicting academic performance of students from VLE big data using deep learning models. Comput. Hum. Behav. 2020, 104, 106189. [CrossRef]

15. Beemt, A.V.D.; Diepstraten, I. Teacher perspectives on ICT: A learning ecology approach. Comput. Educ. 2016, 92, 161-170. [CrossRef]

16. Martínez, N.M.M.; Olivencia, J.J.L.; Meneses, E.L. La realidad aumentada como tecnología emergente para la innovación educativa. Notandum 2017, 125-140. [CrossRef]

17. Keinänen, M.M.; Kairisto-Mertanen, L. Researching learning environments and students' innovation competences. Educ. Train. 2019, 61, 17-30. [CrossRef]

18. Galán, J.G. Education and Virtual Reality. In Advances in Systems Engineering, Signal Processing and Communications; Mastorakis, N., Ed.; WSEAS Press: NewYork, NY, USA, 2002; pp. 345-350.

19. Aparici, R. Mitos de la educación a distancia y de las nuevas tecnologías. RIED. Revista Iberoamericana de Educación a Distancia 2012, 5, 9-27. [CrossRef]

20. Gray, C.; Palaiologou, I. Early Learning in the Digital Age; Sage Publications Limited: London, UK, 2019.

21. Rioseco, M.H.; Roig-Vila, R. Las Expectativas hacia la Integración de las TIC en Educación desde una Perspectiva Fenomenológica. Int. J. Educ. Res. Innov. 2014, 1, $29-40$.

22. Kokkinos, C.M.; Antoniadou, N. Cyber-bullying and cyber-victimization among undergraduate student teachers through the lens of the General Aggression Model. Comput. Hum. Behav. 2019, 98, 59-68. [CrossRef]

23. Throuvala, M.A.; Griffiths, M.D.; Rennoldson, M.; Kuss, D.J. School-based Prevention for Adolescent Internet Addiction: Prevention is the Key. A Systematic Literature Review. Curr. Neuropharmacol. 2019, 17, 507-525. [CrossRef]

24. Masterman, L. Teaching the Media; Routledge: New York, NY, USA, 1990.

25. Buckingham, D. Media Education: Literacy, Learning and Contemporary Culture; Polity Press: Cambridge, UK, 2003.

26. Buckingham, D. Critical pedagogy and media education: A theory in search of a practice. J. Curric. Stud. 1996, 28, 627-650. [CrossRef] 
27. Salomaa, S.; Palsa, L. Media Literacy en Finland; National Media Education Policy, Ministry of Education and Culture: Helsinky, Finland, 2019.

28. Gómez-Galán, J. Nuevos Estilos de Enseñanza en la Era de la Convergencia Tecno-Mediática: Hacia una Educación Holística e Integral. Int. J. Educ. Res. Innov. 2017, 8, 60-78.

29. Lauricella, S.; McAskill, S. Exploring the Potential Benefits of Holistic Education: A Formative Analysis. J. Educ. Altern. 2015, 4, 54-78.

30. Bautista, A.; Ng, S.C.; Múñez, D.; Bull, R. Learning areas for holistic education: Kindergarten teachers' curriculum priorities, professional development needs, and beliefs. Int. J. Child Care Educ. Policy 2016, 10, 78. [CrossRef]

31. Yampolskaya, L.I. The Principle of Holistic Education and the Ideal of a Single Integrated Culture: Towards the Formation of an Approach. Procedia Soc. Behav. Sci. 2015, 166, 488-496. [CrossRef]

32. McLaren, P. La Vida en las Escuelas: Una Introducción a la Pedagogía Crítica en los Fundamentos de la Educación; Siglo XXI Editores: Mexico City, Mexico, 1984.

33. Giroux, H. Pedagogía y Política de la Esperanza: Teoría, Cultura y Enseñanza; Amorrortu Editores: Buenos Aires, Argentina, 2003.

34. López, M.M.L. La pedagogía crítica como propuesta innovadora para el aprendizaje significativo en la educación básica. ReHuSo: Revista de Ciencias Humanísticas y Sociales 2019, 4, 87-98. [CrossRef]

35. Sánchez, N.; Sandoval, E.; Goyeneche, R.; Gallego, D.; Aristizábal, L. La Pedagogía Crítica desde la Perspectiva de Freire, Giroux, y Mclaren: Su Pertinencia en el Contexto de Colombia y América Latina. Espacios 2018, 10,41 .

36. O'Toole, B.; Joseph, E.; Nyaluke, D. Transformative Learning: The Future of Critical Education. In Challenging Perceptions of Africa in Schools; O'Toole, B., Joseph, E., Nyaluke, D., Eds.; Routledge: London, UK, 2019; pp. 178-193.

37. Freire, P. Pedagogy of the Oppressed; Informa UK Limited: London, UK, 2019; pp. 47-54.

38. Pontes, R.F.; Pimenta, S.G. La Pedagogía Crítica de Paulo Freire. Revista Chilena de Pedagogía 2019, 1, 1-15.

39. Del Basto, L.M. Reflexión sobre el Currículo Universitario desde la Teoría Discursiva de la Educación. Revista ieRed: Revista Electrónica de la Red de Investigación Educativa 2005, 1, 1-11.

40. Bridgstock, R. Educating for digital futures: What the learning strategies of digital media professionals can teach higher education. Innov. Educ. Teach. Int. 2014, 53, 1-10. [CrossRef]

41. Wilson, D.; Alaniz, K.; Sikora, J. Digital Media in Today's Classrooms: The Potential for Meaningful Teaching, Learning, and Assessment; Rowman \& Littlefield: Lanham, MD, USA, 2016.

42. Borthwick, A.C.; Hansen, R. Digital Literacy in Teacher Education: Are Teacher Educators Competent? J. Digit. Learn. Teach. Educ. 2017, 33, 46-48. [CrossRef]

43. Nelson, K.; Courier, M.; Joseph, G.W. An Investigation of Digital Literacy Needs of Students. J. Inf. Syst. Educ. 2019, $22,2$.

44. Galán, J.G. Educar en Nuevas Tecnologías y Medios de Comunicación; FEP: Seville-Badajoz, Spain, 2003.

45. McLuhan, M. The Medium is the Massage; Bantam: New York, NY, USA, 1967.

46. Mattelart, A.; Mattelart, M. Pensar sobre los Medios. In Comunicación y Crítica Social; Fundesco: Madrid, Spain, 1987.

47. Negroponte, N.; Harrington, R.; McKay, S.R.; Christian, W. Being Digital. Comput. Phys. 1997, 11, 261. [CrossRef]

48. Castells, M. The Information Age, 3 Vols; Blackwell: Oxford, UK, 1996.

49. Echeverría, J. Los Señores del Aire: Telépolis y el Tercer Entorno; Destino: Barcelona, Spain, 1999.

50. Bauman, Z. Liquid Times: Living in an Age of Uncertainty; John Wiley \& Sons: New York, NY, USA, 2013.

51. Burnett, C.; Merchant, G. Is There a Space for Critical Literacy in the Context of Social Media? Engl. Teach. Pract. Crit. 2011, 10, 41-57.

52. Greenhow, C.; Sonnevend, J.; Agur, C. Education and Social Media: Toward a Digital Future; MIT Press: Cambridge, MA, USA, 2016.

53. Galán, J.G. Educational Research in Higher Education: Methods and Experiences; River Publishers: Aalborg, Denmark, 2016.

54. Freeman, F.N. Visual Education: A Comparative Study of Motion Pictures and other Methods of Instruction; University of Chicago Press: Chicago, IL, USA, 1924. 
55. Deryakulu, D.; Buyukozturk, S.; Karadeniz, S.; Olkun, S. Satisfying and Frustrating Aspects of ICT Teaching: A Comparison based on Self-Efficacy. Int. J. Soc. Manag. Econ. Bus. Eng. 2008, 2, 202-205.

56. Galanouli, D.; Murphy, C.; Gardner, J. Teachers' perceptions of the effectiveness of ICT-competence training. Comput. Educ. 2004, 43, 63-79. [CrossRef]

57. Steiner, D.; Mendelovitch, M. "I'm The Same Teacher": The Attitudes of Science and Computer Literacy Teachers Regarding Integrating ICT in Instruction to Advance Meaningful Learning. Eurasia J. Math. Sci. Technol. Educ. 2016, 13, 1259-1282. [CrossRef]

58. Sánchez-Macías, A.; Veytia, M.G.; Martínez-Cerda, M.L. Integration of ICT in the Mexican Higher Education: The Case of the Virtual Environments of Learning. Int. J. Educ. Excell. 2017, 3, 63-77.

59. Genlott, A.A.; Åke, G.; Viberg, O. Disseminating digital innovation in school-Leading second-order educational change. Educ. Inf. Technol. 2019, 24, 3021-3039. [CrossRef]

60. Prensky, M. How to Teach with Technology: Keeping both Teachers and Students Comfortable in an Era of Exponential Change. In Emerging Technologies for Learning; Becta: Coventry, UK, 2007; pp. 40-46.

61. Galán, J.G. New Perspectives on Integrating Social Networking and Internet Communications in the Curriculum. Elearning Pap. 2011, 26, 1-7.

62. Balazak, M. Teacher's Tasks towards Media Education at School. Trends Educ. 2009 Inf. Technol. Tech. Educ. 2009, 1, 18-25.

63. Fedorov, A.; Levitskaya, A.; Camarero, E. Curricula for Media Literacy Education According to International Experts. Eur. J. Contemp. Educ. 2016, 17, 324-334.

64. Grandío-Pérez, M.M. The Transmedia in University Education: Analysis of the Subjects of Media Education in Spain (2012-2013). Palabra Clave 2016, 19, 85-104. [CrossRef]

65. Antonelli, G.; Di Risio, R.; Di Felice, G. New Media Education: The Contribution of Social Sciences to Training Teachers. In Studies in Systems, Decision and Control; Springer Science and Business Media LLC: Berlin/Heidelberg, Germany, 2016; pp. 417-426.

66. García-Ruiz, R.; Matos, A.; Borges, G. Media Literacy as a Responsibility of Families and Teachers. Media Lit. 2016, 63, 82-91.

67. Veytia, M.G.; Gómez-Galán, J.; Morales, M.B. Competencias Investigativas y Mediación Tecnológica en Doctorandos de Iberoamérica. Int. J. Educ. Res. Innov. 2019, 12, 1-19.

68. Ponce, O.A.; Gómez-Galán, J.; Pagán, N. Current Scientific Research in the Humanities and Social Sciences: Central Issues in Educational Research. Eur. J. Sci. Theol. 2019, 15, 81-95.

69. Simsek, N. Perceptions and Opinions of Educational Technologists Related to Educational Technology. Educ. Technol. Soc. 2005, 8, 170-190.

70. Saez, V. The Media Education in Secondary School from the curricular designs. Entramado 2019, 15, 148-159. [CrossRef]

71. Hsieh, M.-Y. The Most Sustainable Niche Principles of Social Media Education in A Higher Education Contracting Era. Sustainability 2020, 12, 399. [CrossRef]

72. Montoya, A.N. Media Education, Cultural Institution and Nation. Between the Pulpit, the Museum and the Internet. Pedagogía y Saberes 2019, 50, 159-172.

73. Buckingham, D. Teaching media in a 'post-truth' age: Fake news, media bias and the challenge for media/digital literacy education / La enseñanza mediática en la era de la posverdad: Fake news, sesgo mediático y el reto para la educación en materia de alfabetización mediática y digital. Cult. Educ. 2019, 31, 1-19. [CrossRef]

74. Rivera-Rogel, D. Media Education in Latin America. Contratexto 2019, 32, 355-359.

75. Oviedo, P.E.; Cárdenas, F.A.; Zapata, P.N.; Rendón, M.; Rojas, Y.A.; Figueroa, L.F. Estilos de Enseñanza y Estilos de Aprendizaje: Implicaciones para la Educación por Ciclos. Actualidades Pedagógicas 2010, 55, 31-43.

76. Aguilera, E. Los Estilos de Enseñanza, una Necesidad para la Atención de los Estilos de Aprendizaje en la Educación Universitaria. Revista Estilos de Aprendizaje 2012, 10, 79-87.

77. Isaza, L.; Henao, G.C. Actitudes-Estilo de Enseñanza: Su Relación con el Rendimiento Académico. Int. J. Psychol. Res. 2012, 5, 133-141.

78. Peiteado, M.G. Los Estilos de Enseñanza y Aprendizaje como Soporte de la Actividad Docente. J. Learn. Styles 2013, 6, 51-70.

79. Glass, G.V. Meta-analysis: An approach to the synthesis of research results. J. Res. Sci. Teach. 1982, 19, 93-112. [CrossRef] 
80. Hedges, L.V. Advances in statistical methods for meta-analysis. New Dir. Program Eval. 1984, 1984, $25-42$. [CrossRef]

81. Kulik, J.A.; Kulik, C.L. Meta-Analysis in Education. Int. J. Educ. Res. 1989, 13, 221-340. [CrossRef]

82. Moeyaert, M.; Zimmerman, K.N.; Ledford, J.R. Synthesis and Meta-analysis of Single Case Research. In Single Case Research Methodology; Informa UK Limited: London, UK, 2018; pp. 393-416.

83. Leary, H.; Walker, A. Meta-Analysis and Meta-Synthesis Methodologies: Rigorously Piecing Together Research. TechTrends 2018, 62, 525-534. [CrossRef]

(C) 2020 by the author. Licensee MDPI, Basel, Switzerland. This article is an open access article distributed under the terms and conditions of the Creative Commons Attribution (CC BY) license (http://creativecommons.org/licenses/by/4.0/). 